\title{
Development and Evaluation of a New Canine Myocardial Infarction Model Using a Closed- Chest Injection of Thrombogenic Material
}

\author{
Masanori Suzuki; Hironobu Asano; Hideyuki Tanaka; Shinji Usuda, PhD
}

\begin{abstract}
A new canine myocardial infarction model using thrombi induced by closed-chest injection of thrombin and autogenous blood with fibrinogen into coronary arteries was developed. Occlusive thrombi were formed in all treated animals. Occluded vessels did not spontaneously reperfuse 1 day after occlusion, but did so within 3 days. Infarction was confirmed by increased levels of creatine kinase-MB, glutamate-oxaloacetate transaminase anda-hydroxybutyrate dehydrogenase. Additionally, the left ventricular ejection fraction (LVEF) decreased within $0.5 \mathrm{~h}$ after occlusion and had not improved 4 weeks later. After 1 week, extensive transmural anteroinferior myocardial infarction was observed and heart mass had increased. By 4 weeks after occlusion, pulmonary capillary wedge pressure and central venous pressure were increased, and oxygen pressure was decreased. Dropout of nuclei in cardiomyocytes and increased amount of collagen fiber were observed in myocardial infarct regions of hearts excised 4 weeks after occlusion. This canine model may be useful and convenient in evaluating treatment efficacy and the long-term outcome of acute myocardial infarction. (Jpn Circ J 1999; 63: 900-905)
\end{abstract}

Key Words: Cardiac hypertrophy; Coronary artery thrombi; Left ventricular ejection fraction

$\mathbf{T}$ here are few reports about the long-term outcome in animal models of acute myocardial infarction (AMI) with coronary artery thrombi, because of the scarcity of animal models that can examine outcome in this stage. Dogs with coronary artery thrombi, produced after thoracic surgery to deliver a direct injection of a thrombin and autogenous blood mixture into coronary arteries, are generally used to examine the thrombolytic activities of agents., 1,2 They are primarily used as an acute preparation in which thrombi are induced and then reperfused with tissue-type plasminogen activator (t-PA) following an appropriate aging period. A convenient modification of this common method was developed, which uses a closed-chest injection of thrombogenic material directly into coronary vessels. Although coronary artery thrombi were easily prepared without open-chest surgery, the vessels with thrombi remained occluded for more than 1 day, but spontaneously reperfused within 3 days. In the present study, cardiac function, cardiac hypertrophy and cardiovascular performance were evaluated for up to 4 weeks after coronary artery occlusion using the new method, and the utility of the model to assess outcome after occlusion was examined.

\section{Methods}

\section{Induction of Coronary Artery Thrombi} and Confirmation of Patency

All experiments were performed in compliance with the regulations of the Animal Ethics Committee of

(Received April 30, 1999; revised manuscript received July 29, 1999; accepted August 4, 1999)

Applied Pharmacology Research, Pharmacology Laboratories, Yamanouchi Pharmaceutical Co. Ltd, Ibaraki, Japan

Mailing address: Masanori Suzuki, Applied Pharmacology Research, Pharmacology Laboratories, Yamanouchi Pharmaceutical Co. Ltd, 21 Miyukigaoka, Tsukuba, Ibaraki 305-8585, Japan
Yamanouchi Pharmaceutical Co, Ltd. Seventeen adult beagle dogs weighing 9-14kg were used. Animals were anesthetized with thiopental $(20 \mathrm{mg} / \mathrm{kg}$ iv) and anesthesia was maintained with halothane $(0.5-1 \%)$ in room air. Sheaths (Tonokura, Japan) were placed in the common carotid artery and femoral artery for cardiovascular catheter insertion and blood pressure/heart rate monitoring, respectively. Precordial lead ECGs were continuously monitored to detect arrhythmias. A balloon catheter (5Fr; Clinical Supply, Japan) was inserted into the left anterior descending coronary artery distal to the first diagonal branch using an intracoronary wire under fluoroscopy. The catheter has 3 ports and channels: the first for balloon inflation, and the second and third for local delivery of various substances into the artery. Blood flow below the balloon was inhibited by inflation of the balloon. A coronary thrombus was induced by simultaneous injection of thrombin (300 IU; Mochida, Tokyo, Japan) using the second port and channel of the balloon catheter, and autogenous blood with fibrinogen (5 mg; Sigma Chemical, St Louis, MO, USA) using the third one into the coronary artery below the balloon. The balloon was deflated $5 \mathrm{~min}$ after injection. Confirmation of occlusion and reperfusion was performed by angiography $0.5 \mathrm{~h}, 1 \mathrm{~h}, 3 \mathrm{~h}, 6 \mathrm{~h}, 1$ day, 3 days, 1 week or 4 weeks after occlusion. Angiography was performed as follows: A Sones catheter (7Fr; Bird Japan, Japan) was inserted into the left coronary artery and contrast medium (Optiray ${ }^{\circledR}$; Yamanouchi Co, Ltd, Japan) was injected via the cardiovascular catheter under fluoroscopy. Reperfusion was defined as TIMI (thrombolysis in myocardial infarction) grade 2 or 3 and occlusion defined as TIMI grade 0 or 1 ?

In another experiment, tissue-type plasminogen activator (t-PA; Yamanouchi Pharmaceutical Co, Ltd) was administered 1,3 and $6 \mathrm{~h}$ after occlusion to confirm thrombus formation. Reperfusion occurred 10-20 min after treatment with t-PA. 

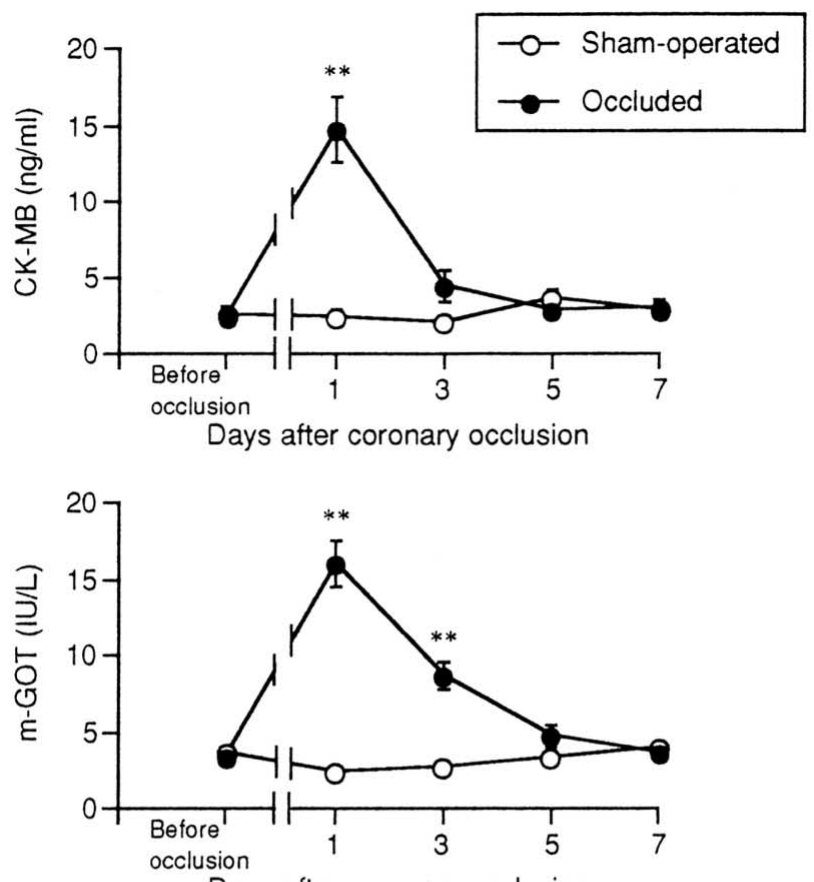

Days after coronary occlusion

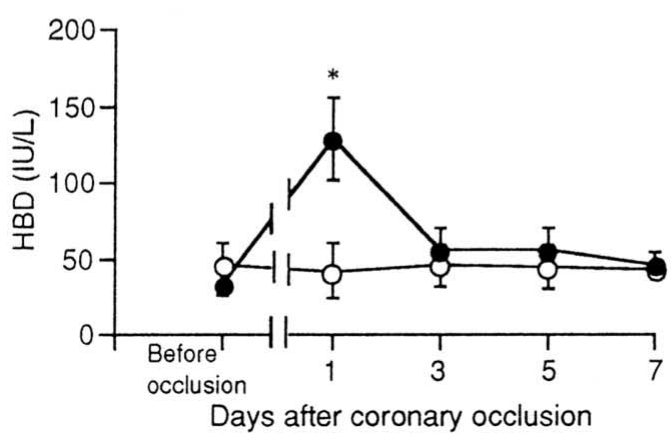

Fig 1. Change in serum CK-MB, m-GOT and HBD in dogs due to coronary artery occlusion. Each value represents the mean $\pm \mathrm{SE}$ $* p<0.05, * * p<0.01$ indicates significant differences from the shamoperated group (Student's t test).

\section{Left Ventricular Ejection Fraction (LVEF)}

Left ventriculography was performed before ballooncatheter insertion, $0.5 \mathrm{~h}, 1$ week and 4 weeks after coronary artery occlusion. A pig-tail catheter (8Fr; Bird Japan) was inserted into the left ventricle and contrast medium (Opitray ${ }^{\circledR}$ ) was injected via the catheter in the $30^{\circ}$ right anterior oblique position (RAO $30^{\circ}$ ) using fluoroscopy. Left ventriculography (LVG) was recorded on video tape (WV-H2, Sony, Japan). Videotaped systolic and diastolic left ventriculography were traced using a KD4300 image analyzer (Graphtec Co, Ltd, Tokyo, Japan) and LVG analysis software (Goodman Co; Nagoya, Japan) was used to determine LVEF.

\section{Pulmonary Capillary Wedge Pressure (PCWP), Central Venous Pressure (CVP) and Oxygen Pressure}

PCWP and CVP were measured before balloon-catheter insertion and 4 weeks after occlusion. A thermodilution catheter (TC-774MP; Nihon-Kohden, Japan) was inserted into the pulmonary artery. PCWP was measured by a $20-\mathrm{s}$ inflation of the balloon at the tip of the catheter and CVP was measured at the catheter side opening, which was

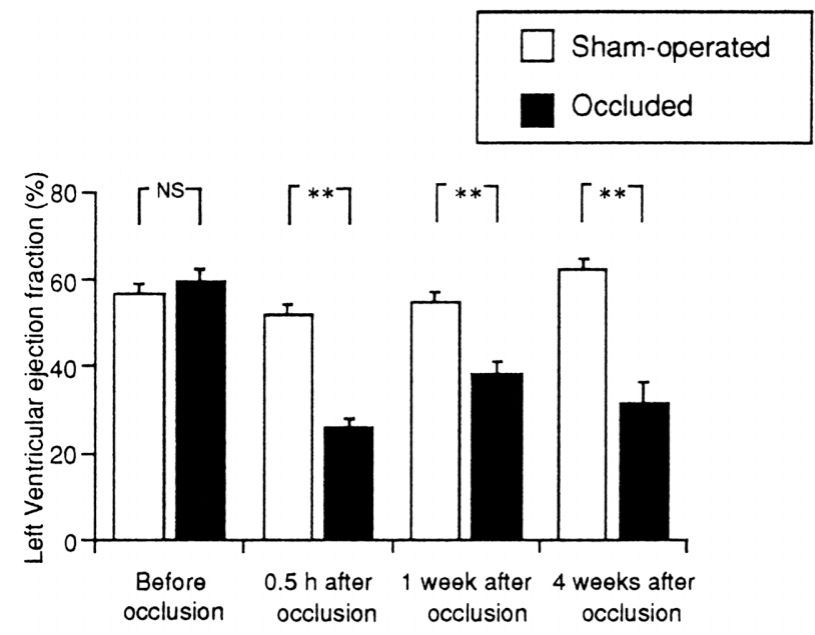

Fig 2. Left ventricular ejection fraction in dogs due to coronary artery occlusion. Each value represents the mean $\pm \mathrm{SE} * * \mathrm{p}<0.01$ indicates significant differences between the groups (Student's t test). NS, no significant difference between the groups (Student's t test).

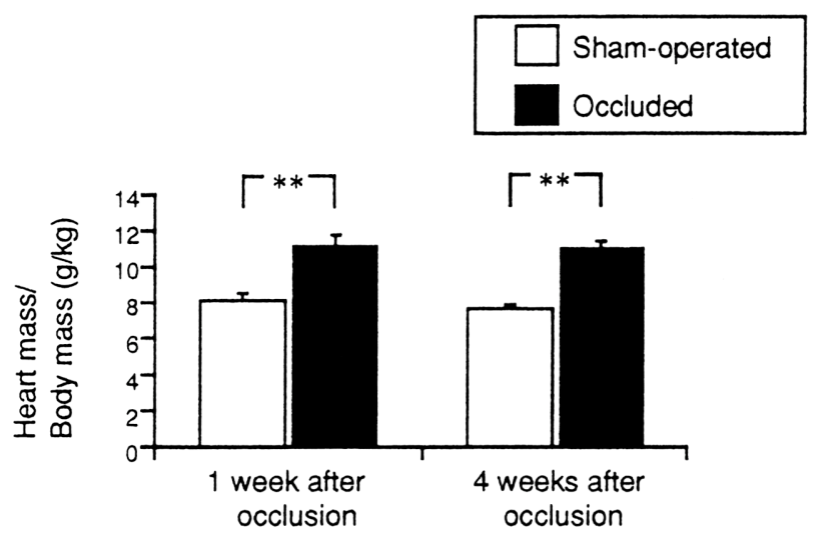

Fig 3. Heart mass in dogs due to coronary artery occlusion. Hearts were excised 1 week or 4 weeks after coronary artery occlusion. Each value represents the mean $\pm \mathrm{SE} * * \mathrm{p}<0.01$ indicates significant differences between the groups (Student's t test).

located in the middle cardiac vein. Blood was withdrawn via the common carotid artery before balloon-catheter insertion and at 4 weeks after coronary artery occlusion for measurement of oxygen pressure, which was measured with an auto-analyzer (Chiron 348; Chiron, Switzerland).

\section{Measurement of Myocardial Enzymes}

Blood was withdrawn before balloon-catheter insertion and 1, 3, 5 and 7 days after occlusion. Serum samples were separated from whole blood and used to measure the myocardial enzyme type and level. Creatine kinase-MB (CK-MB) was measured by chemiluminescent immunoassay, glutamate-oxaloacetate transaminase (m-GOT) was measured by the proteinase $\mathrm{K}$ method ${ }^{5}$ anda-hydroxybutyrate dehydrogenase (HBD) was measured by the RosalkiWilkinson method6

\section{Heart Mass, Myocardial Infarct Area} and Histopathologic Examination

The animals were killed with a lethal dose of sodium pentobarbital 1 week or 4 weeks after coronary artery occlusion and their hearts were excised. The hearts were 
Table 1 Changes in Heart Rate and Mean Blood Pressure in Dogs due to Coronary Artery Occlusion

\begin{tabular}{lcccc}
\hline \hline & Before occlusion & Just after occlusion & 1 week after occlusion & 4 weeks after occlusion \\
\hline Heart rate (beats/min) & & & & \\
$\quad$ Sham-operated & $94.0 \pm 9.3$ & $96.0 \pm 4.0$ & $126.0 \pm 13.0$ & $86.7 \pm 11.7$ \\
$\quad \begin{array}{l}\text { Occluded } \\
\text { Mean blood pressure }(\mathrm{mmHg})\end{array}$ & $84.2 \pm 7.4$ & $93.3 \pm 7.7$ & $75.0 \pm 6.7 * *$ & $110 \pm 7.6$ \\
$\quad$ Sham-operated & $93.9 \pm 7.0$ & $83.7 \pm 5.9$ & $113.6 \pm 8.0$ & $93.6 \pm 8.8$ \\
Occluded & $100.3 \pm 4.4$ & $81.9 \pm 7.0$ & $87.8 \pm 13.1$ & $87.9 \pm 7.1$ \\
\hline
\end{tabular}

Each value represents the mean $\pm S E . * * p<0.01$ indicates significant differences from the sham-operated group (Student's $t$ test).

Table 2 Changes in Pulmonary Capillary Wedge Pressure, Central Venous Pressure and Oxygen Partial Pressure in Dogs due to Coronary Artery Occlusion

\begin{tabular}{lcc}
\hline \hline & Before coronary occlusion & 4 weeks after coronary occlusion \\
\hline Pulmonary capillary wedge pressure $(\mathrm{mmHg})$ & & \\
$\quad$ Sham-operated & $13.7 \pm 1.9$ & $10.7 \pm 1.5$ \\
Occluded & $9.7 \pm 0.9$ & $18.0 \pm 1.2^{*}$ \\
Central venous pressure $(\mathrm{mmHg})$ & $1.0 \pm 0.0$ & $1.0 \pm 0.0$ \\
$\quad$ Sham-operated & $1.0 \pm 0.0$ & $2.0 \pm 0.6$ \\
Occluded & $135.2 \pm 5.4$ & $130.9 \pm 7.4$ \\
Oxygen partial pressure $(\mathrm{mmHg})$ & $143.7 \pm 2.3$ & $113.4 \pm 12.4$ \\
Sham-operated & & \\
Occluded & & \\
\hline
\end{tabular}

Each value represents the mean $\pm S E . *^{*}<0.05$ indicates significant differences from the sham-operated group (Student's $t$ test).

cut into transverse sections $1-\mathrm{cm}$ thick at points 1 and $2 \mathrm{~cm}$ cranial to the apex of the heart. Slices from hearts excised 1 and 4 weeks after occlusion were stained with $1 \%$ TTC (2,3,5-triphenyl tetrazolium chloride; Sigma Chemical) for $5 \mathrm{~min}$ at $37^{\circ} \mathrm{C}$ ? The area of the myocardial infarct was designated as the area that was not stained by TTC. Myocardial infarct areas were calculated using an area measuring program (System Supply; Nagano, Japan). Hearts excised 4 weeks after occlusion were fixed in a $10 \%$ neutrally buffered formaldehyde solution (Nacalai Tesque; Japan). The sections were stained with hematoxylin (Sigma) and eosin (Sigma) and by the Azan-Mallory staining method? Collagen fiber was designated as the area that stained blue using the Azan-Mallory staining method.

\section{Statistics}

The results are expressed as the mean (SE). Statistical analysis of data for intergroup comparison was performed using Student's t test.

\section{Results}

\section{Patency}

Occlusive thrombi were observed in the coronary artery of all animals injected with thrombin and autogenous blood with fibrinogen. Thrombotic coronary occlusion was indicated by an elevated ST segment in the left precordial lead ECG. Spontaneous reperfusion of occluded coronary arteries did not occur for up to 1 day after occlusion. However, spontaneous reperfusion was observed 3 days after occlusion in all animals. No reocclusion after spontaneous reperfusion was observed. In the occluded group $(n=9), 1$ animal died 6 day after occlusion.

\section{Myocardial Enzymes in Serum}

Serum CK-MB increased 6.4 times above normal and HBD increased 3.9 times 1 day after coronary artery occlusion. Enzyme levels decreased to levels similar to those in the sham-operated group within 3 days after occlusion (Fig 1). Serum m-GOT increased by 4.8 times 1 day after occlusion, but decreased to levels similar to those in the sham-operated group within 5 days after occlusion.

\section{LVEF}

LVEF before coronary artery occlusion was $59.7 \pm 2.8 \%$ (Fig 2). It decreased to $26.0 \pm 2.1 \%$ within $0.5 \mathrm{~h}$ after occlusion and was significantly less than the $56.6 \pm 2.4 \%$ value exhibited by the sham-operated group. The decreased LVEF did not improve in either 1 week or 4 weeks after occlusion, showing values of $38.4 \pm 3.0 \%$ and $31.7 \pm 4.6 \%$, respectively.

\section{Heart Mass}

Hearts were excised 1 week or 4 weeks after occlusion. The ratios at 1 week and 4 weeks after occlusion were $11.1 \pm 0.7 \mathrm{~g} / \mathrm{kg}$ and $11.0 \pm 0.4 \mathrm{~g} / \mathrm{kg}$, respectively (Fig 3), which were significantly higher than those in the sham-operated group $(8.1 \pm 0.4 \mathrm{~g} / \mathrm{kg}$ and $7.7 \pm 0.2 \mathrm{~g} / \mathrm{kg}$, respectively).

\section{Cardiovascular Parameters}

No significant differences in heart rate values were observed between the sham-operated and the occluded groups either before occlusion, just after occlusion or 4 weeks after occlusion (Table 1). However, heart rate values at 1 week after occlusion were significantly decreased.

No significant differences in mean blood pressure values were observed between the sham-operated and the occluded groups either before occlusion, just after occlusion or 1 week and 4 weeks after occlusion (Table 1 ).

PCWP significantly increased to $18.0 \pm 1.2 \mathrm{mmHg} 4$ weeks after occlusion, compared with the value $(10.7 \pm 1.5$ $\mathrm{mmHg}$ ) in the sham-operated group (Table 2). CVP increased to $2.0 \pm 0.6 \mathrm{mmHg}$ and oxygen partial pressure decreased to $113.4 \pm 12.4 \mathrm{mmHg} 4$ weeks after occlusion, compared with the values $(1.0 \pm 0.0 \mathrm{mmHg}$ and $130.9 \pm 7.4$ $\mathrm{mmHg}$, respectively) in the sham-operated group. 
a

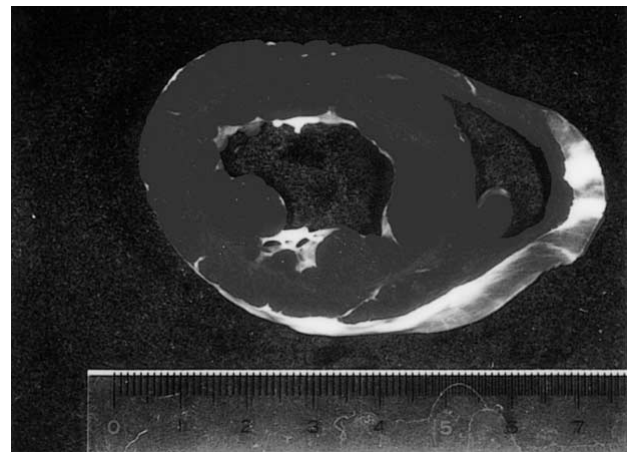

C

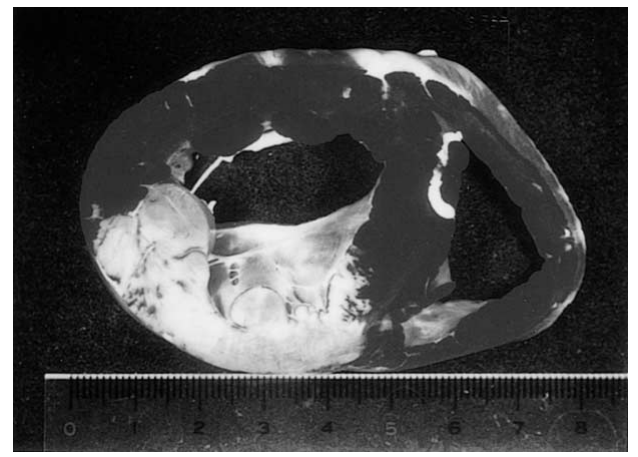

b

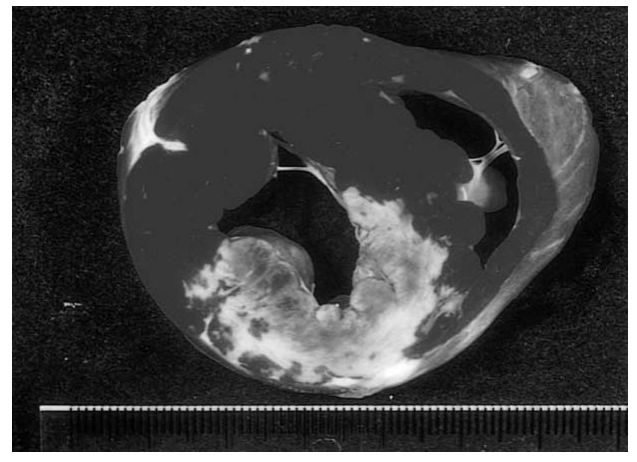

Fig 4. Myocardial infarct development in dogs due to coronary artery occlusion. Hearts were excised (a, b) 1 and (c) 4 weeks after occlusion. (a) Sham-operated control group, (b, c) occluded group. The slices of heart were stained with TTC (2,3,5-triphenyl tetrazolium chloride). The area of the myocardial infarct was the area that was not stained by TTC. Bar $=1 \mathrm{~cm}$.

a

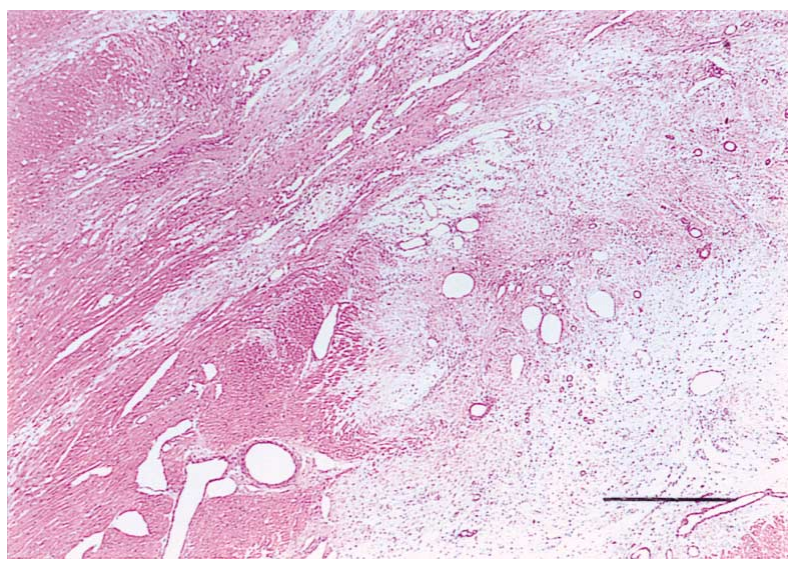

C

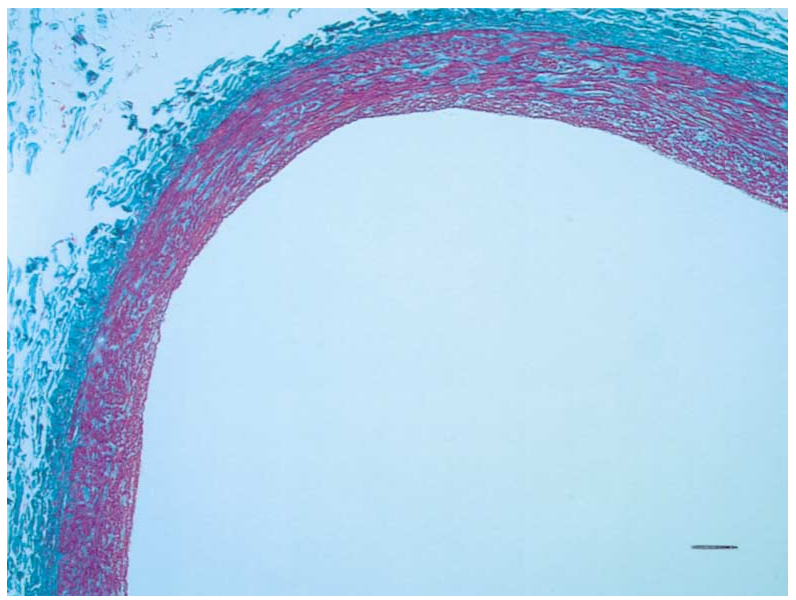

b

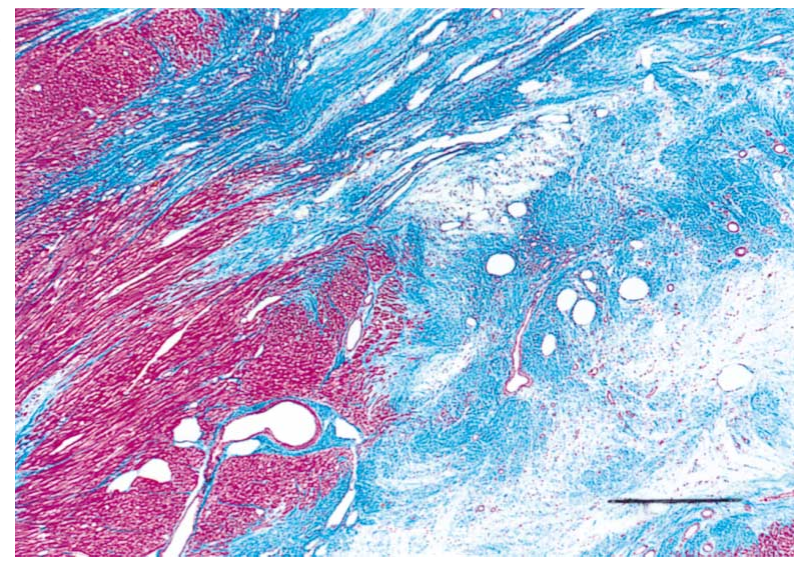

d

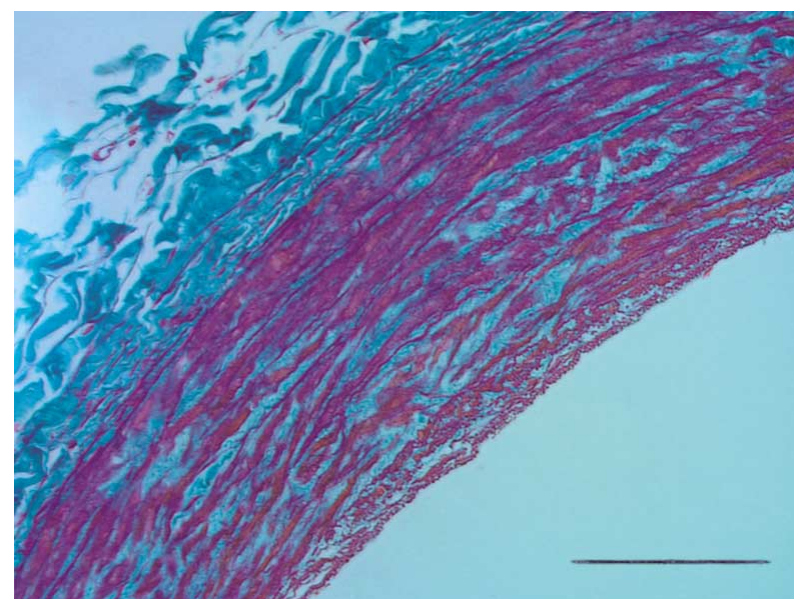

Fig 5. Light microscopic photographs of the transverse section of heart. The hearts were excised 4 weeks after coronary artery occlusion and fixed in formaldehyde solution. (a) Representative slice of heart in the myocardial infarct region (H\&E). Dropout of nuclei in cardiomyocytes was observed. The infarct region can be observed on the right-hand side. (b) Representative slice in myocardial infarct region (Azan-Mallory). The infarcted region can be seen on the right-hand side. Collagen fiber stained blue. (c, d) Representative slice of the left anterior descending coronary artery in the myocardial infarct region (Azan-Mallory). Bars indicate $0.5 \mathrm{~mm}(\mathrm{a}, \mathrm{b})$ and $0.1 \mathrm{~mm}(\mathrm{c}, \mathrm{d})$. 
Myocardial Infarct Development and

\section{Histopathologic Examination}

Extensive transluminal anteroinferior myocardial infarction was observed in all hearts excised after occlusion (Fig 4a,b). The myocardial infarct areas 1 week after the occlusion were $52.3 \pm 8.2 \%$. Slightly thinning of the left ventricular wall 4 weeks after occlusion was observed (Fig 4c). Dropout of nuclei in cardiomyocytes and an increased amount of collagen fiber were observed in the myocardial infarct regions of hearts excised 4 weeks after occlusion. In contrast, increased collagen fiber was not observed in non-infarcted regions (Fig 5a,b). Histopathology also showed that a thin layer of thrombus remained in the left anterior descending coronary artery 4 weeks after occlusion (Fig 5c,d). Although endothelial cells were detached from the basal lamina of coronary artery, damage to the media were less severe.

\section{Discussion}

The coronary artery ligation model ${ }^{9}$ and the coronary artery electrolytic injury model ${ }^{10,11}$ are canine models that could be used to estimate the long-term outcome after coronary occlusion. However, the thoracic surgery in both these models is complicated, and the treated animal is susceptible to infection after operation, increasing the chance of death. It is possible that the canine models using either copperinduced thrombi ${ }^{12-14}$ or thrombi by open-chest injection of a thrombin and autogenous blood mixture ${ }^{1,2}$ could be used. However, they are primarily used as an acute preparation in which thrombi are induced and then reperfused with thrombolytic agents following an appropriate aging period. Therefore, a new canine model employing coronary artery thrombi induced by closed-chest injection of a mixture of thrombin and autogenous blood with fibrinogen was developed. In this model, coronary artery thrombi are easily prepared without open-chest surgery. Occluded vessels do not spontaneously reperfuse the 1 day after occlusion, but do so within 3 days. The thrombus is probably fibrin-rich, because the 2 primary components of the mixture are thrombin and autogenous blood. Vessels occluded with such thrombi reperfuse 10-20 min after treatment with a t$\mathrm{PA}^{1}$, which we confirmed in a preliminary study. Additionally, the ischemic period may be regulated by treatment with thrombolytic agents, which provides an easy way to regulate the severity of tissue damage. Consequently this method holds great promise for the estimation of prognosis of AMI after treatment with thrombolytic agents.

In order to confirm infarction, changes in the levels of serum enzymes were examined in the present study. The amount of many serum enzymes from myocardial tissue increases in the serum during the acute stage of myocardial infarction. CK-MB, which is expressed specifically in myocardium, m-GOT and HBD are used as diagnostic indicators of AMI. In the present study, serum CK-MB, mGOT and HBD transiently increased 1 day after coronary artery occlusion. The changes in the serum enzyme levels with time after coronary artery occlusion were in agreement with previously reported clinical data in patients with AMI ${ }^{15-18}$ which would seem to confirm infarction. Indeed, extensive transmural anteroinferior myocardial infarction was observed. Transmural myocardial infarction develops in dogs after 3-6h of ischemia19,20 Because spontaneous reperfusion did not occur in the present study for up to at least 1 day, most myocardial tissue in the ischemic area would die. Although endothelial cells were detached from the basal lamina of the coronary artery, damage to the media was less severe.

Previous reports indicate that LVEF does not improve in the chronic stage of AMI ${ }^{21-23}$ In the present model, thrombi formed in the left anterior descending coronary artery distal to the first diagonal branch. LVEF decreased $0.5 \mathrm{~h}$ after coronary artery occlusion and did not recover even 4 weeks after occlusion even though the coronary arteries spontaneously reperfused within 3 days after occlusion. This result may be due to development of extensive myocardial infarct.

Heart mass measured at 1 and 4 weeks after coronary artery occlusion significantly increased, which indicates the development of left ventricular hypertrophy, ${ }^{24,25}$ and is in agreement with reports that cardiac hypertrophy occurs in patients with $\mathrm{AMI}^{26,27}$ In the present study, histopathology showed dropout of nuclei from cardiomyocytes and increased amounts of collagen fiber in the infarct area of hearts excised 4 weeks after occlusion 28 This ventricular remodeling could be attributed to the presence of an extensive transmural myocardial infarct ${ }^{29,30}$; however, ventricular remodeling present 4 weeks after occlusion could lead to thinning of the left ventricular wall. Because the true infarct area in such thinned left ventricles may be underestimated, in the present study the infarct area was measured 1 week after occlusion as well, to present a more accurate estimate.

In conclusion, a new technique for assessing the longterm prognosis after myocardial infarction has been developed and tested in dogs. Coronary artery thrombi, induced by closed-chest injection of thrombin and autogenous blood with fibrinogen, were easily prepared without openchest surgery. Vessels with thrombi remained occluded for more than 1 day, but reperfused spontaneously within 3 days. Additionally, occluded vessels could be reperfused rapidly after treatment with thrombolytic agents. Because the ischemic period could be regulated by such thrombolytic treatment, this technique could provide a convenient way to evaluate outcome in the subacute and chronic phases of myocardial infarction after treatment with thrombolytic agents and antiplatelet agents. We hope that this model can be used in long-term studies of myocardial infarction and late reperfusion by thrombolytic treatment 31 Additional extension of this technique using carefully planned and executed concurrent molecular biological, biochemical and physiologic studies could provide excellent insights into the mechanism of cardiac remodeling induced by ischemia.

\section{References}

1. Gold HK, Fallon JT, Yasuda T, Leinbach RC, Khaw BA, Newell JB, et al: Coronary thrombolysis with recombinant human tissue-type plasminogen activator. Circulation 1984; 70: 700-707

2. Gurbel PA, MacCord CS, Anderson RD, Scott H, Atar D, Mergner $\mathrm{W}$, et al: A canine model of acute coronary artery thrombosis for the evaluation of reperfusion strategies. Cardiology 1994; 84: 1-8

3. Chesebro JH, Knatterud G, Roberts R, Borer J, Cohen LS, Dalen J, et al: Thrombolysis in Myocardial Infarction (TIMI) trial, phase I: A comparison between intravenous tissue plasminogen activator and intravenous streptokinase. Circulation 1987; 76: $142-154$

4. Ogihara T, Higaki J, Imai N, Kumahara Y, Murakami K, Mori K, et al: Sensitive direct radio-immunoassay for human renin. J Hypertens 1984; 2(Suppl 2): S239-S241

5. Watazu Y, Uji Y, Okabe H, Shirahase Y, Kaneda N, Karmen A: Proteinase $\mathrm{K}$ inactivation of cytosolic aspartate aminotransferase isoenzyme for measurement of human serum mitochondrial aspartate aminotransferase. J Clin Lab Anal 1993; 7: 81-85

6. Lee ME, Sethna DH, Conklin CM, Shell WE, Matloff JM, Gray RJ: $\mathrm{CK}-\mathrm{MB}$ release following coronary artery bypass grafting in the 
absence of myocardial infarction. Ann Thorac Surg 1983; 35: $277-$ 279

7. Fishbein MC, Meerbaum S, Rit J, Lando U, Kanmatsuse K, Mercier JC, et al: Early phase acute myocardial infarct size quantification: Validation of the triphenyl tetrazolium chloride tissue enzyme staining technique. Am Heart J 1981; 101: 593-600

8. Nakai S, Ishikawa K, Ogawa I, Koka H, Kamata N, Akiyama H, et al: New collateral flow increasing early after coronary occlusion prevented myocardial necrosis in dogs. Heart Vessels 1995; 10: $171-177$

9. Lavallee M, Cox D, Patrick TA, Vatner SF: Salvage of myocardial function by coronary artery reperfusion: 1,2 , and $3 \mathrm{~h}$ after occlusion in conscious dogs. Circ Res 1983; 53: 235-247

10. Cook JJ, Glass JD, Sitko GR, Holahan MA, Stupienski RF 3rd, Wallace AA, et al: Nonpeptide glycoprotein IIb/IIIa inhibitors. 14: Oral antithrombotic efficacy of L-738, 167 in a conscious canine model of coronary artery electrolytic injury. Circulation 1997; 96: 949-958

11. Minami M, Driscoll EM, Lucchesi BR: Antithrombotic effects of BMY21190, an inhibitor of cAMP phosphodiesterase, in a canine model of coronary artery thrombosis. Jpn Circ J 1993; 57: 979-992

12. Kawasaki T, Katoh M, Kaku S, Gushima H, Takenaka T, Yui Y, et al: Thrombolytic activity of a novel modified tissue-type plasminogen activator, YM866, in a canine model of coronary artery thrombosis. Jpn J Pharmacol 1993; 63: 9-16

13. Suzuki S, Saito M, Yui-Y, Kawai C: A novel modified t-PA, E-6010, induces faster recovery of ventricular function after coronary thrombolysis than native t-PA in a canine thrombosis model. Jpn Circ J 1995; 59: 205-212

14. Saito M, Suzuki S, Yui Y, Kawai C: A novel modified tissue-type plasminogen activator (t-PA), E6010, reduces reperfusion arrhythmias induced after coronary thrombolysis-comparison of native t-PA and urokinase. Jpn Circ J 1995; 59: 556-564

15. Ingwall JS: The hypertrophied myocardium accumulates the MBcreatine kinase isozyme. Eur Heart J 1984; 5(Suppl F): 129-139

16. Ingwall JS, Kramer MF, Fifer MA, Lorell BH, Shemin R, Grossman $\mathrm{W}$, et al: The creatine kinase system in normal and diseased human myocardium. N Engl J Med 1985; 313: 1050-1054

17. Lee TH, Goldman L: Serum enzyme assays in the diagnosis of acute myocardial infarction: Recommendations based on a quantitative analysis. Ann Intern Med 1986; 105: 221-233

18. Yamasawa I: Serum enzyme patterns in acute ischemic heart disease with special reference to LDH isoenzymes in intermediate types of ischemic heart disease, fresh myocardial infarction, and cardiogenic shock. Jpn Circ J 1973; 37: 509-531
19. Reimer KA, Lowe JE, Rasmussen MM, Jennings RB: The wavefront phenomenon of ischemic cell death. 1. Myocardial infarct size versus duration of coronary occlusion in dogs. Circulation 1977; 56: 786 794

20. Reimer KA, Jennings RB: The 'wavefront phenomenon' of myocardial ischemic cell death. II. Transmural progression of necrosis within the framework of ischemic bed size (myocardium at risk) and collateral flow. Lab Invest 1979; 40: 633-644

21. Collen D, Lijnen HR, Todd PA, Goa KL: Tissue-type plasminogen activator: A review of its pharmacology and therapeutic use as a thrombolytic agent. Drugs 1989; 38: 346-388

22. Sheehan FH, Doerre R, Schmidt WG, Bolson EL, Uebis R, Von Essen ER, et al: Early recovery of left ventricular function after thrombolytic therapy for acute myocardial infarction: An important determinant of survival. J Am Coll Cardiol 1988; 12: 289-300

23. Topol EJ, Califf RM, Vandormael M, Grines CL, George BS, Sanz ML, et al and Angioplasty in Myocardial Infarction-6 Study Group: A randomized trial of late reperfusion therapy for acute myocardial infarction: Thrombolysis and Angioplasty in Myocardial Infarction-6 Study Group. Circulation 1992; 85: 2090-2099

24. Nishimura H, Kubota J, Okabe M, Ueyama M, Oka T, Kawamura K Long-term alpha 1 blockade does not reverse cardiac hypertrophy in spontaneously hypertensive rats. Jpn Circ J 1993; 57: 898-903

25. Tatebe S, Miyamura H, Sugawara M, Watanabe H, Eguchi S: Induction of right ventricular hypertrophy in neonatal guinea pigs by monocrotaline. Jpn Circ J 1996; 60: 604-608

26. Lavie CJ, O'Keefe JH Jr, Chesebro JH, Clements IP, Gibbons RJ Prevention of late ventricular dilatation after acute myocardial infarction by successful thrombolytic reperfusion. Am J Cardiol 1990; 66: $31-36$

27. White HD, Norris RM, Brown MA, Takayama M, Maslowski A, Bass NM, et al: Effect of intravenous streptokinase on left ventricular function and early survival after acute myocardial infarction. $N$ Engl J Med 1987; 317: 850-855

28. Uusimaa P, Risteli J, Niemela M, Lumme J, Ikaheimo M, Jounela A, et al: Collagen scar formation after acute myocardial infarction: relationships to infarct size, left ventricular function, and coronary artery patency. Circulation 1997; 96: 2565-2572

29. Hochman JS, Buckley BH: Expansion of acute myocardial infarction: An experimental study. Circulation 1982; 65: 1446-1450

30. Pfeffer MA, Braunwald E: Ventricular remodeling after myocardia infarction: Experimental observations and clinical implications. Circulation 1990; 81: 1161-1172

31. Kimura A, Ishikawa K, Ogawa I: Myocardial salvage by reperfusion 12 h after coronary ligation in dogs. Jpn Circ J 1998; 62: 294-298 